\title{
A PROBLEM IN THEORY
}

Michael Muthukrishna ${ }^{1} \&$ Joseph Henrich $^{2,3}$

${ }^{1}$ London School of Economics and Political Science, London, UK

${ }^{2}$ Harvard University, Cambridge, MA, USA

${ }^{3}$ Canadian Institute for Advanced Research (CIFAR), Toronto, ON, Canada

\section{EDITOR'S SUMMARY}

Muthukrishna and Henrich argue that solving the replication crisis in psychology partly requires well-specified, overarching theoretical frameworks. They outline how Dual Inheritance Theory provides one such example that could be adopted by the field.

\section{ABSTRACT}

The replication crisis facing the psychological sciences is widely regarded as rooted in methodological or statistical shortcomings. We argue that a large part of the problem is the lack of a cumulative theoretical framework or frameworks. Without an overarching theoretical framework that generates hypotheses across diverse domains, empirical programs spawn and grow from personal intuitions and culturally-biased folk theories. By providing ways to develop clear predictions, including through the use of formal modelling, theoretical frameworks set expectations that determine whether a new finding is confirmatory, nicely integrating with existing lines of research, or surprising, and therefore requiring further replication and scrutiny. Such frameworks also prioritize certain research foci, motivate the use diverse empirical approaches and, often, provide a natural means to integrate across the sciences. Thus, overarching theoretical 
frameworks pave the way toward a more general theory of human behaviour. We illustrate one such a theoretical framework: Dual Inheritance Theory.

The psychological and behavioural sciences have a problem. By some accounts, half the literature doesn't replicate ${ }^{1}$ and we don't know if the other half replicates for the $88 \%$ of our species who don't live in Western Educated Industrialized Rich Democratic (WEIRD) societies². Although a few researchers insist that all is well ${ }^{3}$, most psychologists acknowledge that a crisis exists and seem to blame it on poor methodological and statistical practices. This leads to proposed solutions like study pre-registration and better reporting policies ${ }^{4}$. We don't disagree that psychology's norms are indeed substandard and that methodological improvements are much needed. Nevertheless, we argue that the crisis runs much deeper and is ultimately rooted in theory or lack thereof. Many subfields within psychology (though not all!) lack any overarching, integrative general theoretical framework that would allow researchers to derive specific predictions from more general premises. Without a general theoretical framework, results are neither expected nor unexpected based on how they fit into the general theory and have no implications for what we expect in other domains.

This situation is thrown into stark relief by comparing psychology textbooks with those in other sciences. Rather than building up principles that flow from overarching theoretical frameworks, psychology textbooks are largely a potpourri of disconnected empirical findings on topics that have been popular at some point in the discipline's history, and clustered based on largely American and European folk categories. Outside of psychology, useful theoretical frameworks tell scientists not only what to expect, but also what not to expect. They show the interconnections between theories. Understanding the mechanisms behind one phenomenon informs research in other areas, often limiting the likely hypotheses or strongly favoring some 
hypotheses over others. Each empirical result reverberates through the interconnected web of our understanding of a domain. Collectively, these interconnected theories tune our intuitions, so we know when something feels "off". When neutrinos appeared to be travelling faster than the speed of light ${ }^{5}$, researchers strongly suspected that something was wrong because this violated the Theory of Special Relativity, which had so nicely accounted for other aspects of the universe. If vinegar and baking soda combined in your child's model volcano didn't produce carbon dioxide and hot ice solution, we suspect something is probably wrong, because this would violate the Periodic Table and "Collision Theory". If we discover fossil rabbits which appear to have originated in the Precambrian era, we would suspect something was wrong, because it conflicts with a cumulative understanding of how species evolved that has nothing to do with previous Precambrian finds per se, but rather with a broad understanding of evolutionary change over time based on how the other pieces fit together.

In contrast, even when derived from a circumscribed theory (e.g. Cognitive Dissonance Theory ${ }^{6}$ ), much psychological research is typically specific and difficult to connect-let alone challenge or support—other findings or theories in the field (e.g. Terror Management Theory ${ }^{7}$ ). Rarely does it contribute to a more general theory of human behavior. Consider this research question: do undergraduates walk slower when they're reminded of the elderly ${ }^{8}$ ? Does this violate a Theory of Human Behavior? What if they walk faster or ambulate unperturbed ${ }^{9}$ ? Can we generalize this to all adult humans? Similarly, if studies show that humans, or at least Americans, prefer fewer choices to many ${ }^{10}$, does this violate any theory at all? What if Germans prefer fewer choices or show no preference ${ }^{11}$ ? Is that a failed replication, another butterfly to be added to the collection of cross-cultural differences, or a confirmation of theory predicting certain kinds of psychological variation? 
With decades of data now under suspicion, without a general and unifying theory of human behavior, we have no principled way to navigate this morass. Pre-registration and multiple replications with larger samples, though a laudable practice, is not a feasible solution to assessing many lifetimes worth of studies. Moreover, without a unifying theoretical framework, we don't know whether we should expect the results to replicate with older individuals, poorer individuals, or individuals in other societies. And without such a framework, even after the onerous replication effort, doubt remains as to whether one of the infinite space of moderators explains the lack of replication. To understand the importance of theory to data and data to theory, it's worth remembering the abductive challenge.

\section{The AbDuctive Process}

Science is built up of facts, as a house is built of stones; but an accumulation of facts is no more a science than a heap of stones is a house. ${ }^{12}$

The present methodological and statistical solutions to the replication crisis will only help ensure solid stones; they don't help us build the house. For that, we need the scaffolding of integrative and cumulative theory. Working without theory leaves us predicting the future based on past results. This is like predicting the position of a planet based on where it was last time. We want to get to celestial mechanics, but that requires using the data to develop the physics of planetary motion in an abductive process.

The scientific process proceeds closer to what Charles Peirce called "abduction" inference to the best explanation - than clean induction or deduction. When faced with a phenomenon, we are faced with incomplete data and a large to infinite space of possible hypotheses. Consider a stylized example of a broken vase in a room. What caused the vase to 
break? One might observe the environment to create a list of possible explanations - the open window, the cat no longer in her basket, the suspiciously quiet toddler watching TV in the next room, and so on. To reduce this space, we may engage in experimentation by placing another vase next to the open window; in ethnographic observation by observing the cat's behavioural patterns; or in an ethological study by interrogating the toddler and observing their reaction to the broken vase. The hypothesis space for any real phenomenon is much larger, but even in our hypothetical space, better theory can far reduce the possible or likely hypotheses and offer explanations we might not consider based on the data alone. Knowing the direction of the window and wind force required to topple a vase can set appropriate priors for that hypothesis; as can understanding how high cats can jump and the toddler's television schedule. Further data collection informs and contributes to these theories.

For more complex phenomenon - why people are religious, the source of ingroup favouritism and outgroup discrimination, and our heuristics and biases and the contexts of their use, the space of possible explanations is impossibly larger, and we cannot hope to build a cumulative science by narrowing it down with guesswork, folk intuitions, verbal logic, or our own limited life experience. A good theoretical framework helps reduce that space. Experiments are arguably the last resort after competing theoretical predictions cannot be distinguished with existing evidence, requiring us to devote resources to a large, well-powered, decisive experiment. The alternative approach leaves us running half a dozen studies with minor variations to eliminate the space of the possible as delimited by the poverty of the researcher's imagination. Such elimination by experimentation is far too inefficient given the need for diverse and reasonable sized samples. In best cases, it is also unlikely to lead to structured cumulative knowledge and in common cases, it can often be systematically misleading. 
Many creative hypotheses have been drawn from the imaginations of researchers from societies that are Western, Educated, Industrialized, Rich and Democratic (WEIRD), but there is a certain circularity to testing these WEIRD intuitions on WEIRD participants that can mislead us into believing we are drawing closer to a deeper and more general understanding of human behaviour. Such an approach led us to believe that fairness means sharing equally in the Ultimatum Game - ubiquitous behaviour in many convenient WEIRD samples - and even attempts to explain how this was part of our evolved psychology. Instead fairness norms systematically vary across societies. ${ }^{13}$ Such an approach led us to believe that facial processing occurs in the right hemisphere of the brain. Instead, strong facial hemispheric lateralization is only present in literate populations, where some of the left hemisphere facial fusiform gyrus was co-opted to allow us to read. ${ }^{14,15}$ As the world approaches $100 \%$ literacy, a psychologist from Venus armed with early $21^{\text {st }}$ century atheoretical approaches to understanding human cognition and with no knowledge of the history of literacy, might discover the Visual Word Form Area and discuss the reading instinct among Homo sapiens just as we do with numeracy, colour perception, and the ability to reason. Is there a better approach to developing theoretical explanations?

\section{TheOrETICAL FrameWORKS, THEORIES, HyPotheses, AND DATA}

The scientific and vernacular meaning of theory are often blurred, particularly in the human sciences. For clarity, we need to distinguish between theoretical frameworks, theories, hypotheses, and data. We will also discuss why it's useful to formalize theories and to distinguish between levels of explanation.

Theoretical frameworks are a broad body of connected theories. Darwin's theory of evolution by natural selection, for example, began as a theory but has grown into a theoretical 
framework. Within the Darwinian framework, multiple theories can be developed that explain some overlapping set of phenomena. For example, there are several competing and complementary theories to explain the evolution of altruism in different species and contexts ${ }^{16}$. These theories are general, unifying explanations for a wide array of available data that allow us to generate additional testable, falsifiable hypotheses_-predictions which allow us to exclude and distinguish between competing theories within the broad framework. These predictions are instantiated in more specific hypotheses that link to mechanisms, which can then be tested using data derived from experiments or other methods of causal inference ${ }^{17}$. There different ways in which theories can be expressed.

Natural Selection as a theory of evolution was first expressed as a verbal argument ${ }^{18}$. But, evolutionary theory has come a long way in the century and a half since the first of Darwin's classics. For example, we now know about genetics and have a much better understanding of the many processes through which species diversify and evolve. Since the Modern Synthesis, evolutionary biology has expressed its theories using analytical and computational models. There are good reasons for why these are useful tools for theory building.

In contrast to high fidelity engineering simulations ${ }^{19}$, quantitative stock market predictions $^{20}$, or probabilistic facial recognition models ${ }^{21}$, many scientists use formal models as aids to thinking through the logic of an argument in order to offer comparative statics, making testable qualitative, but directional predictions about phenomena ${ }^{22-31}$. By formally defining assumptions, logic, and predictions, anyone can challenge the theory by either testing the predictions or by challenging or modifying the assumptions or logic and showing how the predictions would change. Such models, whether analytical or computational, can be thought of as aids to thinking, allowing us to work through the logic and assumptions of systems more complex than our minds can fully represent. And it doesn't take much before this limit is reached. For 
example, inclusive fitness or kin selection seems like a plausible explanation for cooperation among relatives - as long as the genealogical relatedness multiplied by the benefit to the recipient $(r \times b)$ is greater than the personal cost $(c)$, genes for altruism will spread (Hamilton's rule ${ }^{32} ; r b>$ c). What's less obvious without working through the models is why this explanation might only apply under conditions of weak selection ${ }^{33}$, why specific and generalized versions reach different conclusions $^{34,35}$, or indeed the debates around these. An even simpler algebraic example of our cognitive limits, sometimes called the "potato paradox", is as follows: "You have 100kg of potatoes, which are $99 \%$ water by weight. You let them dehydrate until they're $98 \%$ water. How much do they weigh now?" The answer of 50kg is surprising until you work through the algebra. Once you do, the answer seems obvious, tuning our intuitions. Our intuitions can also be shaped by considering levels of explanation.

Levels of explanation, such as the ultimate-proximate heuristic, or Tinbergen's four questions for levels of analysis, are useful distinctions in evolutionary biology. Proximate explanations describe the mechanisms for a phenomenon, whereas Ultimate explanations describe why the phenomenon exists in the first place. A simple illustration is the question of why we enjoy sexual intercourse. A proximate explanation would be something like, "We enjoy pleasurable activities and sex is pleasurable". We could understand this phenomenon in more detail using the tools of neuroscience - when we have sex, oxytocin, dopamine, and other neurochemicals associated with pleasure are released, creating a feeling of euphoria and reinforcing the behaviour. However, none of this tells us why sex and not banging your head against a tree is associated with pleasure. An ultimate explanation would be something like, "Sex is associated with procreation. Animals who enjoyed sex, had more sex, and left more offspring. Animals who preferred banging their heads against a tree instead, left fewer offspring and this preference is no longer with us". 
A more complex example is why religions tend to be pro-fertility ${ }^{36}$. Proximate explanations describe the value of family and community, offering meaning through procreation, and so on. An ultimate explanation reveals how religions that promote fertility grow at the expense of those that do not ${ }^{36}$. If you're American, you may have Quaker friends, probably have Mormon friends, but are unlikely to have Shaking Quaker (Shaker) friends. Mormons, who promoted large families and at one-point polygamy, grew very quickly to 16 million US members. Quakers have attitudes similar to non-religious Americans and have under 100,000 US members. In stark contrast, the Shakers, an offshoot of the Quakers, promoted total celibacy. The Shakers are no longer with us ${ }^{37}$.

The levels interact and sometimes blur (see examples ${ }^{14,38,39}$ ), but some have questioned how useful evolutionary models are for phenomena like memory or vision. It's true that often very high-level functional predictions are used in psychology, but the precision of predictions from evolution about the specifics of mechanisms hinges on the amount of phylogenetic and developmental genetic information available. In bird species, for example, if ecological shifts functionally predict greater male polygyny, you can predict this will result in particular patterns of testosterone regulation (a proximate mechanism, phylogenetically conserved) ${ }^{40}$. Similarly, knowing that human brains are mostly scaled-up primate brains informs the space of possibilities by telling us a lot about what natural selection has to work with in producing human faculties ${ }^{41}$.

A general theory of human behaviour would be evolutionarily plausible (via natural selection under phylogenetic constraints), often utilize formal models, and provide us with an ultimate framework that delivers proximate predictions. In addition to being a crucial part of the abductive scientific process, by forcing, often formally, statements of assumptions and logic, constrained by the broader web of interconnected work, such a framework also contributes to one of the goals of the replication renaissance ${ }^{42}$ - constraining researchers. Rigorous formal theory 
may also be a way to evaluate the existing literature for plausibility based on connections to wellestablished theories and data. It additionally creates a space for theoretical psychologists producing papers that formally develop theories on the back of previous theories to offer strong predictions - a publishable form of pre-registration with greater justification than "we expect this based on our pilot data, past experimental data, life experience, or best guess". What might such a theory look like?

\section{AN ILLUSTRATIVE THEORETICAL FRAMEWORK}

Dual Inheritance Theory, Culture-Gene Coevolutionary Theory, and the expansions in the Extended Evolutionary Synthesis provides a general theoretical framework for the study of human behaviour - a theory of human behaviour to unify the psychological and behavioural sciences ${ }^{14,25,39,43-45}$. The framework draws on the insight of many scientists, ranging from Charles Darwin and Adam Smith to James Baldwin and Donald Campbell ${ }^{46-48}$. It seats humans within the natural world while expanding the toolkit of evolutionary biology to tackle unique aspects of our species, including cumulative culture, social norms, technological change, and institutions. Unlike common applications of evolutionary theory within psychology, this approach is consistent with the rest of the biological sciences, emphasizing the formal modelling of both genetic and cultural evolutionary processes and considering how each influences aspects of psychology with potential feedback loops between culture, genes, and cultural products like institutions, tools, languages, and psychology. Rather than offering primarily post-hoc explanations for existing phenomena based on verbally described evolutionary logic and assumed ancestral conditions, it makes specific a priori predictions about our psychology (as well as temporal and population-level variation in that psychology $y^{2}$ ), which can be (and have been) tested experimentally and observationally $y^{14,39,45}$. The approach is relevant to tackling the WEIRD People Problem ${ }^{2}$ by testing predicted patterns of 
cross-cultural and lifespan variation rather than arbitrarily exploring less WEIRD ${ }^{49}$ sites based on access. We know of no other approach capable of explaining the immense global psychological variation that's recently been documented.

In the 1970s and 1980s several researchers began to adapt the mathematics that had been so profitable in evolutionary biology to understand learning and cultural evolution ${ }^{25,44,50,51}$. One key theoretical insight was to study the evolution of our learning capacities by asking under what conditions or what circumstances natural selection would favour different kinds of learning versus simply inscribing behaviour into genetically programmed developmental processes. An autocatalytic model ${ }^{25}$ revealed a Goldilocks' zone of intermediate environmental variability where the knowledge acquired by parents and grandparents was worth paying attention to despite the learning costs. At one extreme, constantly changing environments require individual trial and error learning while at the other extreme, highly stable environments could be most efficiently navigated by genetically-encoded adaptations. As the data a decade later revealed, between these extremes were precisely the conditions in which our ancestors evolved ${ }^{52,53}$. Subsequent theory and experiments expanded our understanding of the features of this reliance on social learning - from copying without understanding (high fidelity transmission), to selectively copying successful others (pay-off bias), second-order copying (such as copying who others were copying; prestige bias), to copying majorities and pluralities (conformist bias). With moderators, such as changing frequencies, self-relevance, sincerity, and differentially in different domains; to the evolution of an ethnic psychology identifying groups; and a norm psychology for identifying norms and punishing norm violators, and so on ${ }^{14,39,45,54}$. Over time these processes led to information accumulating to the point where not even the brightest among us could recreate the world we lived in. And it led to our psychology and biology being shaped in ways that relied on a rich cultural 
environment that needed to be acquired. Cooking is a clear and compelling example; our guts are too short to survive on raw foods and we can't instinctively distinguish poisonous from edible plants. Yet as the culinary habits of many college students attest, fire-making and cooking are not innate, reliably developing skills.

Together, the formal models underlying these theories offered a theoretical framework to explain human behaviour. Humans, the models suggested, were a new kind of animal, the result of at least two lines of inheritance - a genetic line possessed by all species, and a cumulative cultural line unique to us. These "cultural evolutionary" models of our psychology and behaviour are not analogies of natural selection, population biology, or epidemiology. Rather than a metaphor, they are an example of science proceeding as usual; an extension of natural selection into the realm of human behaviour.

These models made specific, testable predictions. For example, social learning would be favoured when individual learning was costly; humans had an evolved suite of strategies and biases that homed in on the individuals and behaviours with the highest payoff; with individuals deploying these biases, the majority would come to possess a suite of adaptive behaviours that could be copied. And, it was not simply that our species would copy majorities (which Asch and others had begun empirically demonstrating three decades earlier), but that they would specifically do so at a rate higher than the majority - if $60 \%$ of your colleagues use SPSS, you have a greater than $60 \%$ probability of also doing so. Or, you might leave SPSS for R, if you discover your most productive and prestigious colleague is using R. Over the following decades, these predictions were tested using the historical and ethnographic record, as well as both field and laboratory experiments ${ }^{14}$. Here, we illustrate these ideas with two examples from our own work - conformity and choice. 


\section{EXAMPLES: CONFORMITY AND CHOICE}

Asch's seminal line experiments suggested a simple truth: humans tend to conform to majorities. In the half century since the original studies were published, hundreds of experiments have sought to establish the bounds of conformity with more, and more nuanced, moderators identifying when people do and do not conform, distinguishing between normative and informational conformity, identifying which people are more likely to conform, when conformity will be internalized, and so on for many combinations and interactions ${ }^{55,56}$. New hypothetical permutations are limited only by the poverty of the researcher's imagination; science proceeding as a process of hypothesis by imagination and elimination by experimentation. However, because it emerged from a particular experimental paradigm and was only descriptively theorized, the conformity literature has had limited integration with the literatures on persuasion, attitude change, observational learning, childhood imitation or rational decision-making.

In contrast, Dual Inheritance Theory began by asking a fundamental question about learning: when do people use social learning over individual learning, who do they attend to for this learning, and how do they integrate information from other people. This led to the prediction of frequency of different behaviours as a cue about which behaviour, motivation or belief to adopt. To explore this, researcher's developed formal models, including both analytical models and simulations, that permitted conformist learning strategies to compete against other forms of learning 25 . Rather than simply claiming that "humans will copy majorities", these conformist transmission models make a specific prediction - that humans will, under particular conditions, copy majorities at a rate greater than the rate of the behaviour in the population (e.g. a 70\% majority will have a greater than $70 \%$ probability of being copied); thus, conformity will follow a sigmoidal curve (see Figure 1a and Figure 1b). These specific predictions, down to the sigmoidal signature 
of expected behaviour, have been repeatedly demonstrated ${ }^{57-59}$. This non-linear pattern of learning is non-obvious; we may have never discovered it without a mathematical model. But with advances in theory and growing evidence, a result that violated these predictions would be surprising, but publishable in either case, either confirming a specific prediction derived from a general theory (not surprising, but important for cumulative science), or a potentially more important result that violates the evolutionary logic captured by the models. The size of the splash would depend not on how much the results violated people's personal intuitions, but on how many other theoretical predictions and results they brought into question. Such results would invoke extra scrutiny not because they challenged results that gained primacy by temporal precedence in publication, but because they challenged a theory derived from a framework that had made so many other welltested predictions. 


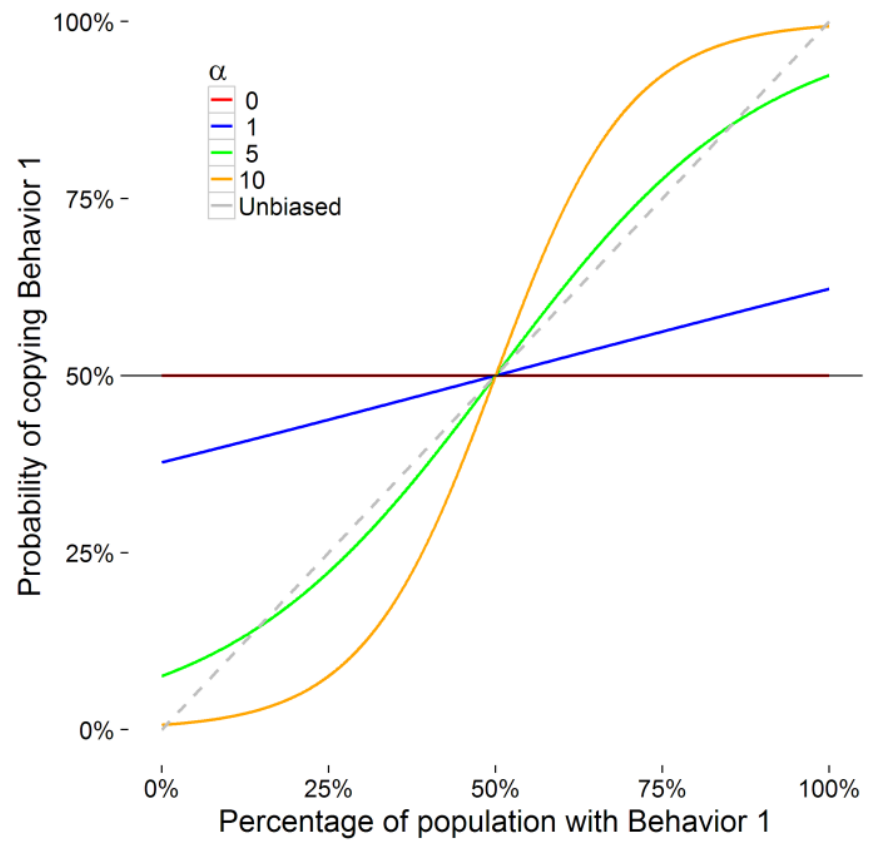

(a)

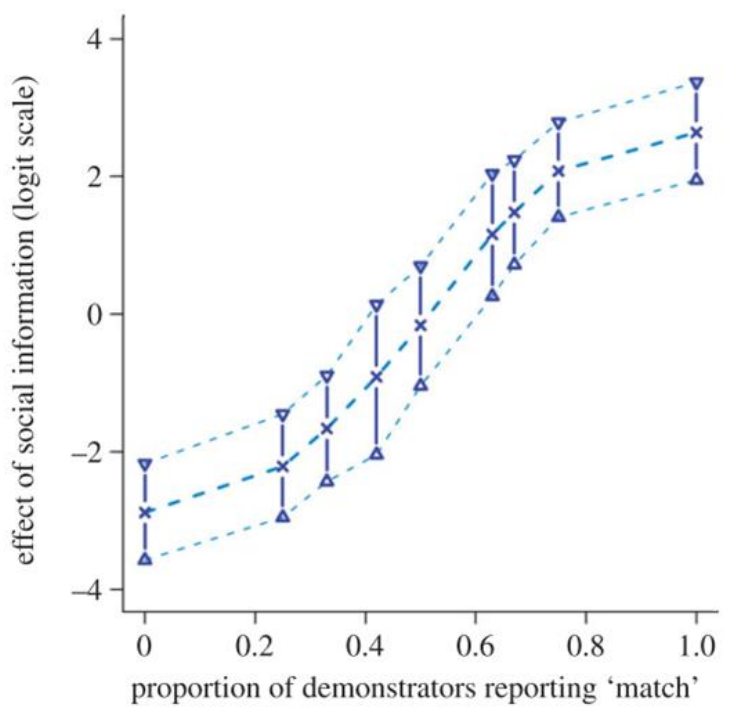

(b)

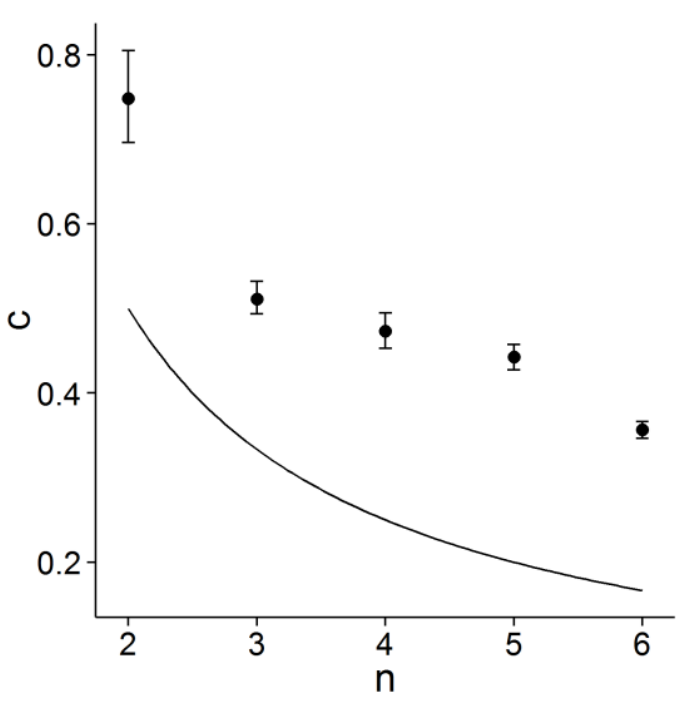

(c)

Figure 1 | Graphs showing theoretical predictions and empirical data for the conformist transmission bias and the shape of the conformist curve with different numbers of choices. (a) A sigmoidal curve of the form $\operatorname{Pr}\left[\right.$ Copying] $=\frac{1}{1+e^{-\alpha\left(b_{1}-c\right)}}$ where $b_{1}$ is the percentage of the population with Behavior 1 (of two behaviors), $c$ is the point at which the probability of 
copying is $\mathbf{5 0 \%}$ ( $c=\mathbf{5 0} \%$ for two traits) and $\alpha$ determines the strength of conformity; a larger $\alpha$ implies that a majority has a larger social influence. The formal prediction is that $\alpha>5$. These models also specify moderators, such as the size of the population, accuracy of the size of the majority ("transmission fidelity") or the importance of the decision ("payoff"). (b) A typical sigmoidal curve from Morgan et al. ${ }^{58}$ Figure 2c; reproduced with permission. (b) Theory (solid line) vs data (points) from Muthukrishna et al. ${ }^{57}$ for the effect of number of choices on the $c$ term of the sigmoidal conformist curve (required plurality for the probability of conforming to reach $50 \%$ ). The data matches the expected pattern, but suggests a prior (raising the $c$ cutoff in the experimental data above the theoretical line). This prior was present in the experiment, but was flat in the theory; an example of science in action-theory informing experiments and experiments informing theory.

Later theories should build on existing theories. Consider an example from the psychology

of choice. One notable line of research began with a question of whether humans prefer or are more likely to make an economic decision with more or less choice ${ }^{10}$. We use this question as an illustration, but it is not unique - the question has many characteristics of a common approach - a hypothesis drawn from a researcher's own life experience (e.g. choice when shopping), with a desire to show something 'sexy' or counterintuitive (that less choice reduces anxiety contra intuitions). This approach has many disadvantages: from WEIRD psychologists using their WEIRD intuitions to generate the alternative hypotheses, contexts, and bounds of the phenomena to the WEIRD participants used to test hypotheses to the specificity of the question itself. A recent meta-analysis ${ }^{11}$ found an effect size of effectively zero for the "paradox of choice", but suggested that some missing moderators may yet reliably explain positive findings. But which moderators? And can these reliably be determined by researchers' mental models and life experience?

From a Dual Inheritance Theory perspective, the question itself is either nonsensical or underspecified. Perhaps in a narrower applied setting, we can gain purchase on when people are more likely to make a purchase, but even here, the guidance of a theoretical framework is useful what is the domain, how important is it, and so on. From a Dual Inheritance Theory perspective, our species has had to make decisions with different numbers of choices to survive. Our decision- 
making strategy will be affected by the importance of the choice (e.g. a consumer reaction to, "30 mortgage options?" of "I guess I don’t need to buy a house," is clearly crazy given the importance of the decision), by the information they have available (e.g. the decisions of others) and indeed, by the number of choices.

In contrast to the common approach discussed above, Nakahashi, Wakano and Henrich ${ }^{60}$ extend the well-established theories of conformity discussed previously to show that the strength of conformist transmission is affected by the number of choices. The same sized plurality will more likely be copied as the number of choices increases, changing the shape of the conformist curve. Theory can also often tune our intuitions in a way that can often be simply expressed (though without important subtleties, one of which is the role of priors in this case)—one aspect of the theory is that as the number of choices $(N)$ increases, choosing any one by chance decreases with the reciprocal of the number of choices $\left(\frac{1}{N}\right)$, so the same consensus on one option is a stronger signal for a greater number of options. Your probability of choosing SPSS with a 60\% majority will be even higher if you discover that the space of possible choices includes not just $\mathrm{R}$, but also SAS, Stata, Python, and Julia. When tested, the model performed exceptionally well (Figure 1c), but also revealed gaps in the theory ${ }^{57}$; science proceeding as usual - theory informing data and vice versa.

\section{OTHER THEORETICAL FRAMEWORKS}

There are of course theoretical frameworks within psychology and other behavioral sciences, though we are perhaps biased in arguing that these too would benefit from integration or even competition with Dual Inheritance Theory. A prominent example of such a framework exists within economics. The much maligned models of 'economic man' or Homo Economicus are a 
theory of human behaviour borne out of $19^{\text {th }}$ century philosophy ${ }^{61}$ and formalized using physicsinspired approaches complete with metaphors of friction and elasticity. Homo Economicus conforms to the requirements of a scientific theory and its assumptions may even make sense in some circumstances. In others, its predictions have been challenged and better models have been built with more realistic assumptions that produce different predictions ${ }^{62-65}$. These predictions are eminently challengeable, because they are formal theoretical predictions easily falsified by the various experiments in the behavioural economics revolution.

Economic models may serve as the Hardy-Weinberg models of human behavior, with assumptions that fit in the absence of culture (indeed, Homo Economicus may be a better model for chimpanzees; Pan Economicus ${ }^{66}$ ). Perhaps due to the formal theory and self-critical statistical and methodological norms of the Credibility Revolution ${ }^{67}$, behavioral economics replicates slightly better than the psychological sciences ${ }^{68}$. The economic approach may be helpful for modeling psychological mechanisms, but would benefit from further constraints on what goes into the model. Rather than including features that affect utility based on WEIRD intuitions, these features would instead be drawn from the web of interconnected evolutionary models that make behavioural predictions. That is, building psychological models from first principles that fit within the scaffolding of a general theoretical framework (for examples, see ${ }^{69,70}$ ).

Within psychology and the broader behavioural sciences too, there are many pockets that have, and are currently, developing and deploying overarching frameworks, often embedded in formal models, that make clear predictions and drive productive research. For example, theories of dual process ${ }^{71}$, perception ${ }^{72,73}$, reinforcement learning ${ }^{74}$, and Bayesian models of cognition ${ }^{75}$. We hope that the frameworks we discuss might inform these theoretical approaches as well, but 
more critically, we hope that shining a light on the problem in theory might also shine a light on the best examples of theory within psychology.

\section{CRITIQUES AND CONCERNS}

Here, we argue that researchers in the psychological and behavioural sciences need to adopt or develop overarching theoretical frameworks and that the failure to operate in such frameworks is central to both the replication crisis and building a more cumulative science. To illustrate, we discussed one example of such a theoretical framework and suggested that it could help unify large swaths of the psychological and behavioural sciences. But, of course, we think the field is wide open and many options should be explored. We are also implicitly advocating a standard abductive scientific approach. This approach should not be controversial, but nevertheless is. Here we outline some of the critiques and concerns we have encountered.

Other fields are suffering from the replication crisis too. The fields hardest hit by the replication crisis are the least theoretical subfields of psychology, such as social psychology ${ }^{1}$, and applied fields such as the medical sciences ${ }^{76,77}$. Like social psychology, the medical sciences lack an overarching theoretical framework. And likewise, medical researchers and evolutionary scientists working at the interface to medicine have made a parallel case for improving the medical sciences through better theory ${ }^{78-82}$.

What about all the findings that have stood the test of time? It's not the case that we cannot learn anything in the absence of theory, any more than we knew nothing about chemistry before Mendeleev's periodic table or biology before Darwin's theory of evolution. Significant and useful knowledge accumulated prior to these theoretical advancements, such as gunpowder and animal breeding. However, these theories and the partial theories that came before them helped 
make sense of the otherwise disconnected data and helped distinguish findings that were likely to stand the test of time from those that will probably not. As was the case in these fields, some previous knowledge will line up nicely with an emerging theoretical framework (animal breeding), while others will be discounted (the alchemy of lead into gold), and others nuanced (alchemy changing one chemical into another).

What about applied science? In an applied context, such as pharmaceutical trials, testing St John's wort, Viagra, or ramipril and showing their efficacy works regardless of origins in traditional knowledge, past side effects, or chemical similarity to previous drugs. Mini-theories and hypotheses based on intuitions or past data can be useful and the applied science of drug safety and efficacy have established useful best practices, such as pre-registration, for identifying the presence and size of an effect and preventing changing hypotheses after seeing the results ${ }^{83}$. However, it is worth nothing that they have not completely solved the replication crisis in these fields $s^{76,77}$.

In a basic science context, in principle these hypotheses or mini-theories could coalesce into a larger overarching theory, but in practice avoidance of others' mini-theories ${ }^{84}$ and a lack of common methods can slow down or prevent a cumulative process. One key advantage to relying on theories of human behaviour in the quest for a cumulative science is that they allow us to interpret past findings in the way that the Periodic Table allowed us to interpret pre-Mendeleev chemical (and alchemical) experiments. We want to move beyond a science that only applies to American undergraduates or Mechanical Turks.

We're not trained to think this way. It is true that many psychologists have less mathematical training than some other social sciences, such as in economics, and certainly less 
than many physical sciences. However, it is also true that our forebears were not trained in statistics that are moving from useful to mandatory in modern psychology. A generation ago this resistance would have applied to the use of anything beyond a t-test and maybe ANOVA. We have an obligation to offer our students the best available tools. There are also many researchers within and outside psychology who have focused on developing behavioural theories that have yet to be tested using our rich empirical toolkit. Psychology departments need to train students for the $21^{\text {st }}$ century and consider hiring theoretical psychologists.

\section{What can evolutionary biology offer beyond what's offered by neuroscience?}

Behavioural scientists may not care about what led to the present state of our species, but only how it operates, and thus may be more convinced by the utility of neuroscience than evolutionary biology. But this assumes that mapping the brain reveals our psychology and behaviour. Humans are a highly cultural species and our brains are as individually and culturally variable as we are. If we are a new kind of animal dependent on two or more lines of inheritance, one of which is culture, neuroscience offers just another way to measure what manifests in our thinking and behaviour.

There are many examples illustrating these neural differences ${ }^{85}$. For English speakers reading letters, the superior temporal gyrus is activated ${ }^{86}$; for Chinese speakers, it's the dorsal extent of the inferior parietal lobe ${ }^{87}$. In a Theory of Mind task, Americans showed greater activation in the right insula, the bilateral temporoparietal junction and the right dorsal medial prefrontal cortex; bilingual Japanese showed greater activation in the right orbital frontal gyrus ${ }^{88}$. Even within the same population, rich, educated brains look different than a more representative sample ${ }^{89}$. In one study, holding someone's hand, even the hand of a stranger attenuated a neural response to threat ${ }^{90}$ - the effect was stronger in stronger marriages. But as it turns out strangers and stronger marriages only attenuate threat if you're a wealthy, well-educated white woman ${ }^{91}$. 
Cultural differences are biologically and neurologically manifested, so looking at brains, hormones or biological measures doesn't get past the influence of culture and cultural evolution.

Can't we solve this problem with Bayesian statistics? Frequentist and Bayesian approaches will tend to give the same answer with uninformative priors. The trouble is having a justifiable reason for one prior over another, opening new researcher degrees of freedom for Bayesian b-hacking ${ }^{92}$. But a Bayesian approach is ideal when we have a priori theory tested by empirical data to inform our prior. Indeed, many cosmologists dealing with one of the messier fields of physics, are only now moving from frequentist to Bayesian statistics, because Bayesian approaches offer more powerful tools for testing their now more well-defined theories with less than ideal datasets ${ }^{93}$.

Can't we solve this problem with Big Data? In the age of Big Data, we can perhaps be surer of our findings - gather solider stones - but lack of theory is just as concerning. Even when you can download and run your analysis on the world, prediction or even description doesn't mean explanation. The space of possible hypotheses and theories remains impossibly large even when your dataset grows. Even if we're now very sure two variables co-vary in the dataset, without knowing why, we have no way of knowing if the relationship will hold in other populations or over time. None of this of course diminishes the importance of data or the value of Big Data approaches, especially for applied problems that are purely about prediction. But, if we want to understand the world, Big Data needs Big Theory.

\section{CONCLUSION}

Some subfields of psychology have traditionally placed a premium on slick studies with surprising results. But 'surprising' should occur with reference to particular hypotheses derived 
from a broader general theory, not based on folk intuitions and theories derived from one's own life experience. Compounding the problem, most psychologists are WEIRD; their lives and intuitions often differ in dramatic ways from those of people in most societies, undercutting our efforts to accumulate knowledge, build a body of theory, and understand human minds and brains more generally ${ }^{2}$. Although there is increasing recognition of the WEIRD people problem and need for more diverse samples ${ }^{94}$, even carefully cataloguing these cross-cultural differences brings us no closer to understanding the sources of those differences. Moreover, humans vary between and within societies ${ }^{95}$. Without an underlying theoretical framework from which to draw hypotheses and tune our intuitions, it is difficult to distinguish results that are unusual and interesting, from results that are unusual and probably wrong.

We use Dual Inheritance Theory and its extensions as an example of a theoretical framework and though it is not the only one, there are arguably advantages to an evolutionary approach. Humans are an evolved species and Dobzhansky's ${ }^{96}$ maxim applies as much to our psychology as to our anatomy and physiology—Nothing makes sense except in the light of evolution. Like all other species on the planet, all aspects of our behaviour must in some way flow from the evolutionary processes that led to our present state. Dual Inheritance Theory, CultureGene Coevolutionary Theory and the Extended Evolutionary Synthesis's growing body of theoretical and empirical research offers several predictions and exclusions for our psychology.

Evolutionary approaches have explicitly theorized about learning, cultural evolution, conflicting incentives, competition, ecological effects, and the interaction between genes and culture $^{14,25,97-105}$. In addition to traditional domains, such as mating, kinship, and reciprocity, recent evolutionary theory integrates insights on several topics germane to psychology ${ }^{106}$. These frameworks also allow us to connect otherwise disparate areas of research. For example, research 
on social learning can help us understand imitation in children and adults, and the many biases in social influence, conformity, and persuasion ${ }^{57,58,107-111}$. Research on norm psychology can shed light on other aspects of social influence, conformity, and persuasion, as well as the content of stereotypes and attitudes ${ }^{112-114}$. Research on our ethnic psychology informs research on cooperation, stereotyping, essentialism, intergroup conflict, and prosocial behavior ${ }^{115-121}$. Other integrative research informs core topics such as motivation ${ }^{101,122,123}$, decision-making biases, individual-differences, language, and intelligence $e^{57,108,124-128}$.

This approach seamlessly integrates the biological and social sciences. The same techniques can be used to study cetaceans ${ }^{129}$, fish ${ }^{130}$, apes ${ }^{111}$ and past and future humans ${ }^{128,131}$. The social sciences can also begin to inform the biological sciences through what shapes cultural, epigenetic, and microbiome effects. For example, the selection pressure for larger human brains ${ }^{128,131}$ can explain why emergency Cesareans and other birth interventions are best predicted by head size ${ }^{132}$. Cesareans may remove a physical barrier to larger brains, but at the cost of reducing the mother to child microbiome inheritance ${ }^{133}$. Institutional and political structures can have multigenerational epigenetic effects on physical ${ }^{134}$ and mental health ${ }^{135}$.

Our expanding understanding of the evolution of our norm psychology ${ }^{112}$ and ethnic psychology ${ }^{115}$, are beginning to help us theorize about the line between norms and institutions, answering questions about cross-national differences in corruption ${ }^{136,137}$, switching between norms ${ }^{138}$, and the relationships between formal and informal institutions. For example, the Church's ban on polygynous marriage and the subsequent impact on normative monogamy on testosterone, patience, risking taking, crime and rise of democratic institutions ${ }^{139}$. This research has implications for law, political science, economics, and history from individual cognition to societal institutions and back again. New projects are also bringing the humanities to bear on long- 
standing questions by building large databases in religion and cultural evolution ${ }^{140,141}$. The first step on this ladder integrating the human sciences is building on this general theory of human behaviour, but there are many steps to go. Drawing from and contributing to these theories allows us to make sense of decades of now distrusted data, repair our reputation, and move toward a more general understanding of human psychology and behaviour.

\section{REFERENCES}

1 Open Science Collaboration. Estimating the reproducibility of psychological science. Science 349, aac4716 (2015).

2 Henrich, J., Heine, S. J. \& Norenzayan, A. The weirdest people in the world? Behavioral and Brain Sciences 33, 61-83 (2010).

3 Gilbert, D. T., King, G., Pettigrew, S. \& Wilson, T. D. Comment on "Estimating the reproducibility of psychological science". Science 351, 1037-1037 (2016).

4 Munafò, M. R. et al. A manifesto for reproducible science. Nature Human Behaviour 1, 0021, doi:10.1038/s41562-016-0021 (2017).

5 Agafonova, N. et al. Measurement of the neutrino velocity with the OPERA detector in the CNGS beam. JHEP 1210, 093, doi:10.1007/JHEP10(2012)093 (2012).

6 Festinger, L. A theory of cognitive dissonance. Vol. 2 (Stanford university press, 1962).

7 Solomon, S., Greenberg, J. \& Pyszczynski, T. in Advances in experimental social psychology Vol. 24 93-159 (Elsevier, 1991).

8 Bargh, J. A., Chen, M. \& Burrows, L. Automaticity of social behavior: Direct effects of trait construct and stereotype activation on action. Journal of personality and social psychology 71, 230 (1996).

9 Doyen, S., Klein, O., Pichon, C.-L. \& Cleeremans, A. Behavioral Priming: It's All in the Mind, but Whose Mind? PLoS ONE 7, e29081, doi:10.1371/journal.pone.0029081 (2012).

10 Schwartz, B. \& Kliban, K. The paradox of choice: Why more is less. (Ecco, 2004).

11 Scheibehenne, B., Greifeneder, R. \& Todd, P. M. Can there ever be too many options? A meta-analytic review of choice overload. Journal of Consumer Research 37, 409-425 (2010).

12 Poincaré, H. Science and bypothesis. (Science Press, 1905).

13 Henrich, J. et al. Markets, religion, community size, and the evolution of fairness and punishment. Science 327, 1480-1484 (2010).

14 Henrich, J. The secret of our success: How culture is driving buman evolution, domesticating our species, and making us smarter. (Princeton University Press, 2016).

15 Dehaene, S. Reading in the brain: The new science of how we read. (Penguin, 2009).

16 Fletcher, J. A. \& Doebeli, M. A simple and general explanation for the evolution of altruism. Proceedings of the Royal Society B: Biological Sciences 276, 13-19, doi:10.1098/rspb.2008.0829 (2009).

17 Shipley, B. Cause and correlation in biology: a user's guide to path analysis, structural equations and causal inference with R. (Cambridge University Press, 2016).

18 Darwin, C. On the origins of species by means of natural selection. London: Murray (1859).

19 MSC Software. Dytran, <http://www.mscsoftware.com/product/dytran> (2004). 
Chan, E. Quantitative trading: how to build your own algorithmic trading business. Vol. 430 (John Wiley \& Sons, 2009).

21 Liu, C. \& Wechsler, H. Gabor feature based classification using the enhanced fisher linear discriminant model for face recognition. Image processing, IEEE Transactions on 11, 467-476 (2002).

22 Hastie, R. \& Kameda, T. The Robust Beauty of Majority Rules in Group Decisions. Psychological Review 112, 494-508, doi:10.1037/0033-295X.112.2.494 (2005).

23 Kendal, J., Giraldeau, L.-A. \& Laland, K. The evolution of social learning rules: payoff-biased and frequency-dependent biased transmission. Journal of Theoretical Biology 260, 210-219 (2009).

24 Aoki, K. \& Feldman, M. W. Evolution of learning strategies in temporally and spatially variable environments: a review of theory. Theoretical population biology 91, 3-19 (2014).

25 Boyd, R. \& Richerson, P. J. Culture and the evolutionary process. (University of Chicago Press, 1985).

26 MacCoun, R. J. The burden of social proof: Shared thresholds and social influence. Psychological review 119, 345 (2012).

27 Nowak, A., Szamrej, J. \& Latané, B. From private attitude to public opinion: A dynamic theory of social impact. Psychological Review 97, 362-376, doi:10.1037/0033-295X.97.3.362 (1990).

28 Tanford, S. \& Penrod, S. Computer modeling of influence in the jury: The role of the consistent juror. Social Psychology Quarterly 46, 200-212 (1983).

29 Tanford, S. \& Penrod, S. Social Influence Model: A formal integration of research on majority and minority influence processes. Psychological Bulletin 95, 189-225, doi:10.1037/00332909.95.2.189 (1984).

30 Smaldino, P. E., Calanchini, J. \& Pickett, C. L. Theory development with agent-based models. Organizational Psychology Review 5, 300-317 (2015).

31 Murphy, S. C. et al. The role of overconfidence in romantic desirability and competition. Personality and Social Psychology Bulletin 41, 1036-1052 (2015).

32 Hamilton, W. D. The genetical evolution of social behaviour. II. Journal of theoretical biology 7, 17-52 (1964).

33 Traulsen, A. Mathematics of kin - and group - selection: formally equivalent? Evolution: International Journal of Organic Evolution 64, 316-323 (2010).

34 Birch, J. Hamilton's rule and its discontents. The British Journal for the Philosophy of Science 65, 381-411 (2013).

35 Nowak, M. A., McAvoy, A., Allen, B. \& Wilson, E. O. The general form of Hamilton's rule makes no predictions and cannot be tested empirically. Proceedings of the National Academy of Sciences, 201701805 (2017).

36 Norenzayan, A. et al. The cultural evolution of prosocial religions. Behavioral and brain sciences 39, e1 (2016).

37 Bidgood, J. in The New York Times (New York, 2017).

38 Laland, K. N., Sterelny, K., Odling-Smee, J., Hoppitt, W. \& Uller, T. Cause and effect in biology revisited: is Mayr's proximate-ultimate dichotomy still useful? science 334, 1512-1516 (2011).

39 Laland, K. N. Darwin's unfinished symphony: how culture made the human mind. (Princeton University Press, 2017).

40 Wingfield, J. C., Lynn, S. E. \& Soma, K. K. Avoiding the 'costs' of testosterone: ecological bases of hormone-behavior interactions. Brain, behavior and evolution 57, 239-251 (2001).

41 Gabi, M. et al. No relative expansion of the number of prefrontal neurons in primate and human evolution. Proceedings of the National Academy of Sciences 113, 9617-9622 (2016). 
42 Nelson, L. D., Simmons, J. \& Simonsohn, U. Psychology's Renaissance. Annual Review of Psychology 69, 511-534, doi:10.1146/annurev-psych-122216-011836 (2018).

43 Laland, K. N. et al. The extended evolutionary synthesis: its structure, assumptions and predictions. Proc. R. Soc. B 282, 20151019 (2015).

44 Cavalli-Sforza, L. L. \& Feldman, M. W. Cultural transmission and evolution: a quantitative approach. (Princeton University Press, 1981).

45 Boyd, R. A different kind of animal: how culture transformed our species: how culture transformed our species. (Princeton University Press, 2017).

46 Campbell, D. T. On the conflicts between biological and social evolution and between psychology and moral tradition. American psychologist 30, 1103 (1975).

47 Campbell, D. T. Variation and selective retention in socio-cultural evolution. Social Change in Developing Area (1965).

48 Campbell, D. T. Blind variation and selective retentions in creative thought as in other knowledge processes. Psychological review 67, 380 (1960).

49 Muthukrishna, M. et al. Beyond WEIRD Psychology: Measuring and Mapping Scales of Cultural and Psychological Distance. SSRN, doi:https://ssrn.com/abstract=3259613 (2018).

50 Lumsden, C. J. \& Wilson, E. O. Genes, mind, and culture: The coevolutionary process. (Harvard University Press, 1981).

51 Pulliam, H. R. \& Dunford, C. Programmed to learn: An essay on the evolution of culture. (Columbia University Press, 1980).

52 Richerson, P. J., Bettinger, R. L. \& Boyd, R. Evolution on a restless planet: Were environmental variability and environmental change major drivers of human evolution. Handbook of evolution 2, 223-242 (2005).

53 Zachos, J., Pagani, M., Sloan, L., Thomas, E. \& Billups, K. Trends, Rhythms, and Aberrations in Global Climate 65 Ma to Present. Science 292, 686-693, doi:10.1126/science.1059412 (2001).

54 Chudek, M., Muthukrishna, M. \& Henrich, J. in The Handbook of Evolutionary Psychology Vol. 2 (ed David M. Buss) Ch. 30, (John Wiley and Sons, 2015).

55 Cialdini, R. B. \& Goldstein, N. J. Social influence: Compliance and conformity. Annual Review of Psychology 55, 591-621 (2004).

56 Bond, R. \& Smith, P. B. Culture and conformity: A meta-analysis of studies using Asch's (1952b, 1956) line judgment task. Psychological Bulletin 119, 111-137, doi:10.1037/00332909.119.1.111 (1996).

57 Muthukrishna, M., Morgan, T. J. H. \& Henrich, J. The When and Who of Social Learning and Conformist Transmission. Evolution and Human Behavior 37, 10-20 (2016).

58 Morgan, T., Rendell, L., Ehn, M., Hoppitt, W. \& Laland, K. The evolutionary basis of human social learning. Proceedings of the Royal Society B: Biological Sciences 279, 653-662 (2012).

59 Efferson, C., Lalive, R., Richerson, P. J., McElreath, R. \& Lubell, M. Conformists and mavericks: the empirics of frequency-dependent cultural transmission. Evolution and Human Behavior 29, 56-64 (2008).

60 Nakahashi, W., Wakano, J. Y. \& Henrich, J. Adaptive social learning strategies in temporally and spatially varying environments. Human Nature 23, 386-418 (2012).

61 Persky, J. Retrospectives: the ethology of homo economicus. The journal of economic perspectives, 221-231 (1995).

62 Henrich, J. et al. In search of homo economicus: behavioral experiments in 15 small-scale societies. American Economic Review, 73-78 (2001).

63 Kahneman, D. \& Tversky, A. Prospect theory: An analysis of decision under risk. Econometrica: Journal of the Econometric Society, 263-291 (1979). 
Gintis, H. Beyond Homo economicus: evidence from experimental economics. Ecological economics 35, 311-322 (2000).

65 Thaler, R. H. From homo economicus to homo sapiens. The Journal of Economic Perspectives, 133141 (2000).

66 Jensen, K., Call, J. \& Tomasello, M. Chimpanzees are rational maximizers in an ultimatum game. science 318, 107-109 (2007).

67 Angrist, J. D. \& Pischke, J.-S. The credibility revolution in empirical economics: How better research design is taking the con out of econometrics. Journal of economic perspectives 24, 3-30 (2010).

68 Camerer, C. F. et al. Evaluating replicability of laboratory experiments in economics. Science 351, 1433-1436, doi:10.1126/science.aaf0918 (2016).

69 Besley, T. \& Persson, T. Democratic Values and Institutions. Working Paper (2016).

70 Francois, P. \& Zabojnik, J. Trust, social capital, and economic development. Journal of the European Economic Association 3, 51-94 (2005).

71 Bear, A. \& Rand, D. G. Intuition, deliberation, and the evolution of cooperation. Proceedings of the National Academy of Sciences of the United States of America 113, doi:10.1073/pnas.1517780113 (2015).

72 Gold, J. I. \& Shadlen, M. N. Neural computations that underlie decisions about sensory stimuli. Trends in Cognitive Sciences 5, 10-16, doi:10/bw4p5n (2001).

73 Heeger, D. J. Theory of cortical function. Proceedings of the National Academy of Sciences 114, 17731782, doi:10/f9wqpj (2017).

74 Dayan, P. \& Niv, Y. Reinforcement learning: The Good, The Bad and The Ugly. Current Opinion in Neurobiology 18, 185-196, doi:10/c2bzz2 (2008).

75 Griffiths, T. L., Kemp, C. \& Tenenbaum, J. B. in The Cambridge Handbook of Computational Psychology (ed Ron Sun) 59-100 (Cambridge University Press, 2008).

76 Freedman, L. P., Cockburn, I. M. \& Simcoe, T. S. The Economics of Reproducibility in Preclinical Research. PLOS Biology 13, e1002165, doi:10.1371/journal.pbio.1002165 (2015).

77 Reproducibility Project: Cancer Biology. Reproducibility Project: Cancer Biology, < https:/ / elifesciences.org/collections/9b1e83d1/reproducibility-project-cancer-biology $>$ (2018).

78 Lea, A. J., Tung, J., Archie, E. A. \& Alberts, S. C. Developmental plasticity: Bridging research in evolution and human health. Evolution, Medicine, and Public Health 2017, 162-175, doi:10.1093/emph/eox019 (2017).

79 Wells, J. C. K., Nesse, R. M., Sear, R., Johnstone, R. A. \& Stearns, S. C. Evolutionary public health: introducing the concept. The Lancet 390, 500-509, doi:10.1016/S0140-6736(17)30572$\mathrm{X}(2017)$.

80 Gluckman, P., Beedle, A., Buklijas, T., Low, F. \& Hanson, M. Principles of evolutionary medicine. (Oxford University Press, 2016).

81 Stearns, S. C., Nesse, R. M., Govindaraju, D. R. \& Ellison, P. T. Evolutionary perspectives on health and medicine. Proceedings of the National Academy of Sciences 107, 1691-1695, doi:10/bpc263 (2010).

82 Nesse, R. M. et al. Making evolutionary biology a basic science for medicine. Proceedings of the National Academy of Sciences 107, 1800-1807, doi:10/d3crt7 (2010).

83 Kerr, N. L. HARKing: Hypothesizing after the results are known. Personality and Social Psychology Review 2, 196-217 (1998).

84 Mischel, W. The toothbrush problem. Association for Psychological Science Observer 21 (2009).

85 Han, S. H. et al. A Cultural Neuroscience Approach to the Biosocial Nature of the Human Brain. Annu Rev Psychol 64, 335-359 (2013). 
86 Bolger, D. J., Perfetti, C. A. \& Schneider, W. Cross-cultural effect on the brain revisited: Universal structures plus writing system variation. Human brain mapping 25, 92-104 (2005).

87 Tan, L. H., Laird, A. R., Li, K. \& Fox, P. T. Neuroanatomical correlates of phonological processing of Chinese characters and alphabetic words: A meta-analysis. Human brain mapping 25, 83-91 (2005).

88 Kobayashi, C., Glover, G. H. \& Temple, E. Cultural and linguistic influence on neural bases of 'Theory of Mind': an fMRI study with Japanese bilinguals. Brain and language 98, 210-220 (2006).

89 LeWinn, K. Z., Sheridan, M. A., Keyes, K. M., Hamilton, A. \& McLaughlin, K. A. Sample composition alters associations between age and brain structure. Nature Communications 8, 874, doi:10.1038/s41467-017-00908-7 (2017).

90 Coan, J. A., Schaefer, H. S. \& Davidson, R. J. Lending a hand: Social regulation of the neural response to threat. Psychological science 17, 1032-1039 (2006).

91 Coan, J. A. et al. Relationship status and perceived support in the social regulation of neural responses to threat. Social Cognitive and Affective Neuroscience 12, 1574-1583, doi:10.1093/scan/nsx091 (2017).

92 Savalei, V. \& Dunn, E. Is the call to abandon p-values the red herring of the replicability crisis? Frontiers in Psychology 6, 245, doi:10.3389/fpsyg.2015.00245 (2015).

93 Trotta, R. Bayes in the sky: Bayesian inference and model selection in cosmology. Contemporary Physics 49, 71-104 (2008).

94 Nielsen, M., Haun, D., Kärtner, J. \& Legare, C. H. The persistent sampling bias in developmental psychology: A call to action. Journal of Experimental Child Psychology 162, 31-38 (2017).

95 Talhelm, T. et al. Large-scale psychological differences within China explained by rice versus wheat agriculture. Science 344, 603-608 (2014).

96 Dobzhansky, T. Nothing in biology makes sense except in the light of evolution. American Biology Teacher 35, 125-129 (1973).

97 Wilson, M. \& Daly, M. Competitiveness, risk taking, and violence: The young male syndrome. Ethology and sociobiology 6, 59-73 (1985).

98 Daly, M. \& Wilson, M. Homicide. (Transaction Publishers, 1988).

99 Richerson, P. J. \& Boyd, R. Not by genes alone: How culture transformed buman evolution. (University of Chicago Press, 2005).

100 Barkow, J. H., Cosmides, L. \& Tooby, J. (Oxford University Press, Oxford, UK, 1992).

101 Cosmides, L. \& Tooby, J. Evolutionary psychology: new perspectives on cognition and motivation. Annual review of psychology 64, 201 (2013).

102 Confer, J. C. et al. Evolutionary psychology: Controversies, questions, prospects, and limitations. American Psychologist 65, 110 (2010).

103 Fincher, C. L., Thornhill, R., Murray, D. R. \& Schaller, M. Pathogen prevalence predicts human cross-cultural variability in individualism/collectivism. Proceedings of the Royal Society B: Biological Sciences 275, 1279-1285 (2008).

104 Hruschka, D. et al. Impartial Institutions, Pathogen Stress and the Expanding Social Network. Human Nature 25, 567-579 (2014).

105 Laland, K. N., Odling-Smee, J. \& Myles, S. How culture shaped the human genome: bringing genetics and the human sciences together. Nature Reviews Genetics 11, 137-148 (2010).

106 Buss, D. M. The Handbook of Evolutionary Psychology. (Wiley, 2015).

107 Hoppitt, W. \& Laland, K. N. Social Learning: An Introduction to Mechanisms, Methods, and Models. (Princeton University Press, 2013). 
108 Boyd, R., Richerson, P. J. \& Henrich, J. The cultural niche: Why social learning is essential for human adaptation. Proceedings of the National Academy of Sciences 108, 10918-10925 (2011).

109 Nielsen, M., Subiaul, F., Galef, B., Zentall, T. \& Whiten, A. Social learning in humans and nonhuman animals: theoretical and empirical dissections. Journal of Comparative Psychology 126, 109 (2012).

110 Whiten, A., McGuigan, N., Marshall-Pescini, S. \& Hopper, L. M. Emulation, imitation, overimitation and the scope of culture for child and chimpanzee. Philosophical Transactions of the Royal Society B: Biological Sciences 364, 2417-2428 (2009).

111 Claidière, N. \& Whiten, A. Integrating the study of conformity and culture in humans and nonhuman animals. Psychological bulletin 138, 126 (2012).

112 Chudek, M. \& Henrich, J. Culture-gene coevolution, norm-psychology and the emergence of human prosociality. Trends in cognitive sciences 15, 218-226 (2011).

113 Schmidt, M. F. \& Tomasello, M. Young children enforce social norms. Current Directions in Psychological Science 21, 232-236 (2012).

114 Brown, G. R., Dickins, T. E., Sear, R. \& Laland, K. N. Evolutionary accounts of human behavioural diversity. Philosophical Transactions of the Royal Society B: Biological Sciences 366, 313324 (2011).

115 McElreath, R., Boyd, R. \& Richerson, P. J. Shared norms and the evolution of ethnic markers. Current Anthropology 44, 122-130 (2003).

116 Efferson, C., Lalive, R. \& Fehr, E. The coevolution of cultural groups and ingroup favoritism. Science 321, 1844-1849 (2008).

117 Moya, C. Evolved priors for ethnolinguistic categorization: A case study from the QuechuaAymara boundary in the Peruvian Altiplano. Evolution and Human Behavior 34, 265-272 (2013).

118 Atran, S. \& Henrich, J. The Evolution of Religion: How Cognitive By-Products, Adaptive Learning Heuristics, Ritual Displays, and Group Competition Generate Deep Commitments to Prosocial Religion. Biological Theory 5, 18-30 (2010).

119 Bell, A. V., Richerson, P. J. \& McElreath, R. Culture rather than genes provides greater scope for the evolution of large-scale human prosociality. Proceedings of the National Academy of Sciences 106, 17671-17674 (2009).

120 Norenzayan, A. \& Shariff, A. F. The origin and evolution of religious prosociality. science 322, 58-62 (2008).

121 Richerson, P. et al. Cultural Group Selection Plays an Essential Role in Explaining Human Cooperation: A Sketch of the Evidence. Behavioral and Brain Sciences 39 (2016).

122 Tooby, J., Cosmides, L., Sell, A., Lieberman, D. \& Sznycer, D. in Handbook of approach and avoidance motivation Vol. 251 (Lawrence Erlbaum Mahwah, NJ, 2008).

123 von Hippel, W. \& Trivers, R. The evolution and psychology of self-deception. Behavioral and Brain Sciences 34, 1-16 (2011).

124 Buss, D. M. How can evolutionary psychology successfully explain personality and individual differences? Perspectives on Psychological Science 4, 359-366 (2009).

125 Rand, D. G., Greene, J. D. \& Nowak, M. A. Spontaneous giving and calculated greed. Nature 489, 427-430 (2012).

126 Whiten, A. \& Erdal, D. The human socio-cognitive niche and its evolutionary origins. Philosophical Transactions of the Royal Society of London B: Biological Sciences 367, 2119-2129 (2012).

127 Pinker, S. The language instinct: The new science of language and mind. Vol. 7529 (Penguin UK, 1995).

128 Muthukrishna, M. \& Henrich, J. Innovation in the collective brain. Philosophical Transactions of the Royal Society of London B: Biological Sciences 371, doi:10.1098/rstb.2015.0192 (2016).

129 Fox, K. C., Muthukrishna, M. \& Shultz, S. The social and cultural roots of whale and dolphin brains. Nature ecology \& evolution (2017). 
130 Laland, K. N., Atton, N. \& Webster, M. M. From fish to fashion: experimental and theoretical insights into the evolution of culture. Philosophical Transactions of the Royal Society B: Biological Sciences 366, 958-968 (2011).

131 Muthukrishna, M., Doebeli, M., Chudek, M. \& Henrich, J. The Cultural Brain Hypothesis: How culture drives brain expansion, sociality, and life history. PLOS Computational Biology (forthcoming).

132 Lipschuetz, M. et al. A large head circumference is more strongly associated with unplanned cesarean or instrumental delivery and neonatal complications than high birthweight. American journal of obstetrics and gynecology 213, 833. e831-833. e812 (2015).

133 Dominguez-Bello, M. G. et al. Partial restoration of the microbiota of cesarean-born infants via vaginal microbial transfer. Nature medicine 22, 250 (2016).

134 Ravelli, G.-P., Stein, Z. A. \& Susser, M. W. Obesity in young men after famine exposure in utero and early infancy. New England Journal of Medicine 295, 349-353 (1976).

135 St Clair, D. et al. Rates of adult schizophrenia following prenatal exposure to the Chinese famine of 1959-1961. Jama 294, 557-562 (2005).

136 Muthukrishna, M., Francois, P., Pourahmadi, S. \& Henrich, J. Corrupting cooperation and how anti-corruption strategies may backfire. Nature Human Behaviour 1, 0138 (2017).

137 Muthukrishna, M. Corruption, Cooperation, and the Evolution of Prosocial Institutions. SSRN, doi:http://dx.doi.org/10.2139/ssrn.3082315 (2017).

138 Henrich, J. Cultural group selection, coevolutionary processes and large-scale cooperation. Journal of Economic Behavior \& Organization 53, 3-35 (2004).

139 Henrich, J., Boyd, R. \& Richerson, P. J. The puzzle of monogamous marriage. Philosophical Transactions of the Royal Society B: Biological Sciences 367, 657-669 (2012).

140 Slingerland, E. \& Sullivan, B. Durkheim with Data: The Database of Religious History. Journal of the American Academy of Religion 85, 312-347 (2017).

141 Sullivan, B., Muthukrishna, M., Tappenden, F. S. \& Slingerland, E. Exploring the challenges and potentialities of the database of religious history for cognitive historiography. Journal of Cognitive Historiography 3 (2016).

\section{COMPETING INTERESTS}

The authors declare no competing interests.

\section{ACKNOWLEDGEMENTS}

We would like to thank Tim Besley, Natasha Griffiths, Steve Heine, Keith Jensen, Kevin Laland, Daniel Muthukrishna, Stephanie Salgado, and Jennifer Sheehy-Skeffington for their helpful comments. 